\title{
Molecular evidence for absence of Y-linkage of the Hairy Ears trait
}

\author{
Andrew C Lee ${ }^{1}$, Angamuthu Kamalam ${ }^{2}$, Susan M Adams ${ }^{1}$ and Mark A Jobling ${ }^{\star 1}$ \\ ${ }^{1}$ Department of Genetics, University of Leicester, University Road, Leicester LE1 7RH, UK; ${ }^{2}$ Annamalai Colony, \\ Virugambakkam, Chennai 600092, India
}

The human Hairy Ears phenotype has traditionally been regarded as the only Y-linked heritable trait. Here, we use Y-chromosomal DNA binary-marker haplotyping to show that a cohort of southern Indian HairyEared males carries $Y$ chromosomes from many haplogroups of the $Y$-phylogeny, which, under a hypothesis of $Y$ linkage, would require multiple independent mutations within a single population. We further show that there is no significant difference between the Y-haplogroup spectrum in Hairy-Eared males and that in a geographically matched control sample of unaffected males. The trait cannot, therefore, be Y-linked in southern Indians, and by extension, is unlikely to be so in any population. European Journal of Human Genetics (2004) 12, 1077-1079. doi:10.1038/sj.ejhg.5201271

Published online 15 September 2004

Keywords: Hairy Ears; Y chromosome; haplogroups; India; association study

\section{Introduction}

For over 40 years there has been debate over the mode of inheritance of the human Hairy Ears trait (Hypertrichosis Pinnae Auris (MIM 139500 or 425500)), attracting the early interest of such luminaries as Curt Stern ${ }^{1,2}$ and JBS Haldane, ${ }^{3}$ and characterized by the unusual feature of several geneticists studying themselves and their own families. ${ }^{4-6}$

The trait involves the development of hairs on the outside of the pinna of the ear, and observation of simple holandric (father-to-son) inheritance in a five-generation Italian pedigree reported $^{7}$ in 1907 suggested that this phenotype was Y-linked. As has recently been discussed, ${ }^{8}$ Hairy Ears was one of a set of 17 examples of suggested Ylinkage later re-examined by Stern ${ }^{1}$ and generally debunked. However, while Stern was categorical in his rejection of most of the traits, his opinion on Hairy Ears was that 'judgement may well be postponed'. Subsequently, southern Indian pedigrees ${ }^{4}$ showed strong

*Correspondence: Dr MA Jobling, Department of Genetics, University of Leicester, Adrian Building, University Road, Leicester LE1 7RH, UK. Tel: + 44 (0)116 252 3377; Fax: + 44 (0)116 252 3378;

E-mail: maj4@leicester.ac.uk

Received 3 May 2004; revised 10 June 2004; accepted 25 June 2004 evidence of Y-linkage, but there were later complications including claimed illegitimacies, ${ }^{3}$ apparently reduced penetrance, variability in diagnostic criteria, age-dependence of onset, cosmetic hair removal ${ }^{9}$ and secondary ear-baldness. ${ }^{2}$ Crucially, some pedigrees appeared to show that daughters (unaffected) of affected males were unable to pass on the trait, ${ }^{10}$ consistent with Y-linkage rather than the alternative hypothesis of sex-limited expression of an autosomal dominant gene. However, more recently, three female subjects have been described who themselves manifest a form of the trait. ${ }^{11}$ Despite this confusion, Hairy Ears is still widely discussed in textbooks under the heading of Y-linkage (eg Griffiths et $a^{12}$ ).

Here, we use a novel means to address this long-standing question by asking whether there is any association between this putatively Y-linked phenotype and Y-chromosomal DNA haplotype.

\section{Materials and methods}

Buccal swab samples were obtained with informed consent from 50 Hairy-Eared males and 50 unaffected males, both groups being ascertained by visual inspection. DNA was extracted using the QiaAmp DNA mini-kit (Qiagen). 


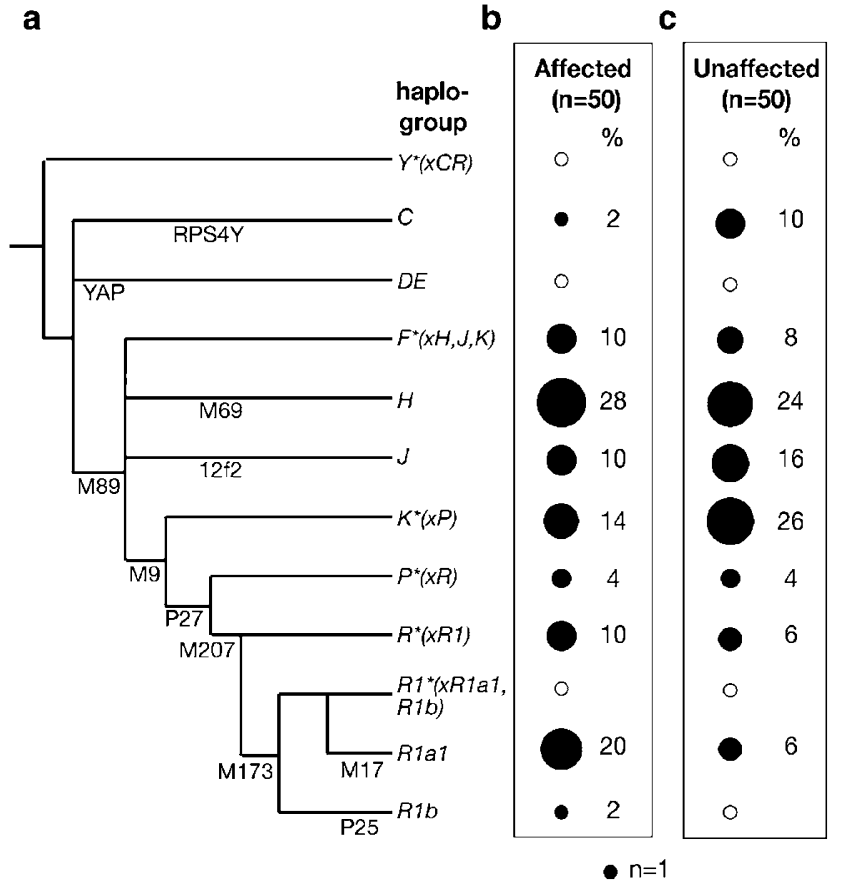

Figure 1 Y-chromosomal haplogroups in Hairy-Eared and unaffected control males. (a) Binary marker phylogeny of the $Y$ chromosome, showing mutations on the branches of the tree, and haplogroup names ${ }^{16}$ to the right. (b) Haplogroup profile of a cohort of 50 unrelated Hairy-Eared males. Areas of filled circles are proportional to haplogroup frequency, and unfilled circles indicate unobserved haplogroups. Percentages are given to the right of circles. (c) Haplogroup profile of a control cohort of 50 unrelated unaffected males.

Y-chromosomal binary markers (see Figure 1a) were typed either by methods listed previously, ${ }^{13}$ or by the SNaPshot (Applied Biosystems) minisequencing method using modified versions of primers already described, ${ }^{14}$ and analysis on an ABI3100 platform (Applied Biosystems).

Haplogroup frequencies in case and control groups were compared using the Arlequin package ${ }^{15}$ by a population differentiation test, analogous to Fisher's exact test.

\section{Results}

We hypothesized that if the generally rare trait of Hairy Ears were indeed Y-linked, then manifesting males within a given population would be likely to share the same causative mutation on the $\mathrm{Y}$ chromosome. Since the male-specific portion of the $\mathrm{Y}$ chromosome is nonrecombining, this would imply that all affected males should belong to a particular Y-chromosomal lineage (haplogroup), as defined by binary markers representing unique events in human evolution. Although a number of cases have been reported from other parts of the world, the trait is particularly prevalent in southern India, where in one study it was found in almost $35 \%$ of males. ${ }^{11}$ We therefore haplotyped a cohort of 50 unrelated Hairy-Eared males from the region around Chennai, India, using 11 Y-chromosomal binary markers ${ }^{16}$ (Figure 1a).

The markers define a possible 12 haplogroups. Figure $1 \mathrm{~b}$ shows that the affected males belong not to a single haplogroup, but to nine distinct haplogroups spread widely in the $\mathrm{Y}$ chromosome phylogeny and with a time to most recent common ancestor estimated at $68500 \pm 6000$ years ago. ${ }^{17}$ If the trait is indeed Y-linked, then we must assume that there have been multiple causative mutations within this single population, and this therefore strongly suggests that the trait is not linked to the Y chromosome.

We then compared the haplogroup frequencies of the affected males with those of 50 unaffected unrelated males from the same geographical region (Figure 1c). Judged by a population differentiation test, ${ }^{15}$ there is no statistically significant difference between the two groups $(P=0.20)$ further refuting any possible association between the $\mathrm{Y}$ chromosome and the Hairy Ears trait.

\section{Discussion}

Given this evidence against Y-linkage, and the obvious influence of hormones upon sexual dimorphism in bodyhair patterns, sex-limited expression of an autosomal (or pseudoautosomal) dominant trait seems the most parsimonious explanation of the mode of inheritance of Hairy Ears in southern Indians. If this is so, rigorous pedigree analysis is expected to reveal the passage of the trait via nonmanifesting females. An alternative explanation, which would account for the occasional incidences of affected females, ${ }^{11}$ would be partial sex linkage: a dominant allele at a pseudoautosomal locus close to the boundary with sex-specific DNA could occasionally exchange between the sex chromosomes and therefore occur on $\mathrm{Y}$ chromosomes of different haplogroups and also on $\mathrm{X}$ chromosomes. However, given the high frequency of the trait and the variety of $\mathrm{Y}$ haplogroups with which it is associated, we would expect to see more female subjects than the very few that have so far been observed; also, the potential candidate genes in the proximal parts of the pseudoautosomal regions are far from promising.

This study also suggests that, in the absence of strong evidence to the contrary, cases of Hairy Ears in other populations should be regarded by default as not Y-linked. It is worth noting that a recent comprehensive cataloging of genes on the $\mathrm{Y}$ chromosome ${ }^{18}$ reveals no persuasive candidates for hypertrichotic phenotypes. Our findings contribute another nail to Stern's ${ }^{1}$ coffin of Y-linked traits, but two heritable traits still remain: one is the interesting 
and novel example of nonsyndromic hearing impairment recently reported in a large Chinese pedigree; ${ }^{19}$ the other, paradoxically, and thanks to modern reproductive therapy, is one certainly not envisaged by Stern - natural male infertility. ${ }^{20}$

\section{Acknowledgements}

MAJ was supported by a Wellcome Trust Senior Fellowship in Basic Biomedical Science (grant no. 057559), and ACL and SMA by the Wellcome Trust. We thank the participants, Professor AS Thambiah for his courtesy in allowing subject recruitment, and Elena Bosch for help with haplotyping.

\section{References}

1 Stern C: The problem of complete Y-linkage in man. Am J Hum Genet 1957; 9: 147-166.

2 Stern C, Centerwall WR, Sarkar SS: New data on the problem of Ylinkage of hairy pinnae. Am J Hum Genet 1964; 16: 455-471.

3 Dronamraju KR, Haldane JBS: Inheritance of hairy pinnae. Am J Hum Genet 1962; 14: 102-103.

4 Dronamraju KR: Hypertrichosis of the pinna of the human ear, Y-linked pedigrees. J Genet 1960; 57: 230-244.

5 Gates RR, Bhaduri PN: The Inheritance of Hairy Ear Rims, Mankind Quarterly, Mankind Monographs No.1, Edinburgh, 1961.

6 Rao DC: Hypertrichosis of the ear rims: two remarks on the twogene hypothesis. Acta Genet Med Gemellol 1972; 21: 216-220.

7 Tommasi C: Ipertricosi auricolare famigliare. Arch Psichiatr Neuropat Antropol Crim Med Legale 1907; 28: 60-67.

8 Page DC: 2003 Curt Stern Award Address: on low expectations exceeded; or, the genomic salvation of the Y chromosome. Am J Hum Genet 2004; 74: 399-402.
9 Sarkar SS, Banerjee AR, Bhattacharjee P, Stern C: A contribution to the genetics of hypertrichosis of the ear rims. Am J Hum Genet 1961; 13: 214-223.

10 Gates RR, Chakravartti MR, Mukherjee DR: Final pedigrees of Ychromosome inheritance. Am J Hum Genet 1962; 14: 363-375.

11 Kamalam A, Thambiah AS: Genetics of hairy ears in South Indians. Clin Exp Dermatol 1990; 15: 192-194.

12 Griffiths AJF, Miller JH, Suzuki DT, Lewontin RC, Gelbart WM: An introduction to genetic analysis. W.H. Freeman \& Co.: New York, 1996.

13 Rosser ZH, Zerjal T, Hurles ME et al: Y-chromosomal diversity within Europe is clinal and influenced primarily by geography, rather than by language. Am J Hum Genet 2000; 67: 1526-1543.

14 Paracchini S, Arredi B, Chalk R, Tyler-Smith C: Hierarchical highthroughput SNP genotyping of the human Y chromosome using MALDI-TOF mass spectrometry. Nucl Acids Res 2002; 30: e27.

15 Schneider S, Roessli D, Excoffier L: Arlequin ver. 2.0: a software for population genetics data analysis. Geneva, Switzerland: Genetics and Biometry Laboratory, University of Geneva, 2000.

16 Y Chromosome Consortium. (Ellis N, Hammer M, Hurles ME et $a l)$ : A nomenclature system for the tree of human Ychromosomal binary haplogroups. Genome Res 2002; 12: 339348.

17 Hammer MF, Zegura SL: The human Y chromosome haplogroup tree: nomenclature and phylogeny of its major divisions. Annu Rev Anthropol 2002; 31: 303-321.

18 Skaletsky H, Kuroda-Kawaguchi T, Minx PJ et al: The male-specific region of the human Y chromosome: a mosaic of discrete sequence classes. Nature 2003; 423: 825-837.

19 Wang $\mathrm{QJ}, \mathrm{Lu} \mathrm{CY}, \mathrm{Li} \mathrm{N}$ et al: Y-linked inheritance of nonsyndromic hearing impairment in a large Chinese family. J Med Genet 2004; 41: E80.

20 Page DC, Silber S, Brown LG: Men with infertility caused by AZFC deletion can produce sons by intracytoplasmic sperm injection, but are likely to transmit the deletion and infertility. Hum Reproduct 1999; 14: 1722-1726. 